Check for updates

Cite this: RSC Adv., 2019, 9, 4172

\title{
Enhancement of protein stability by an additional disulfide bond designed in human neuroglobin $\dagger$
}

Received 19th December 2018 Accepted 28th January 2019

DOI: $10.1039 / c 8 r a 10390 a$

rsc.li/rsc-advances

\author{
Hai-Xiao Liu, (D) a Lianzhi Li, (D) ${ }^{b}$ Xin-Zhi Yang, ${ }^{c}$ Chuan-Wan Wei, ${ }^{a}$ Hui-Min Cheng, ${ }^{a}$ \\ Shu-Qin Gao, ${ }^{c} \mathrm{Ge}-\mathrm{Bo}$ Wen ${ }^{\mathrm{c}}$ and Ying-Wu Lin (D) *ac
}

Human neuroglobin ( $\mathrm{Ngb}$ ) forms an intramolecular disulfide bond between Cys46 and Cys55, with a third Cys120 near the protein surface, which is a promising protein model for heme protein design. In order to protect the free Cys120 and to enhance the protein stability, we herein developed a strategy by designing an additional disulfide bond between Cys120 and Cys15 via A15C mutation. The design was supported by molecular modeling, and the formation of Cys15-Cys120 disulfide bond was confirmed experimentally by ESI-MS analysis. Molecular modeling, UV-Vis and CD spectroscopy showed that the additional disulfide bond caused minimal structural alterations of Ngb. Meanwhile, the disulfide bond of Cys15Cys120 was found to enhance both $\mathrm{Gdn} \cdot \mathrm{HCl}$-induced unfolding stability (increased by $\sim 0.64 \mathrm{M}$ ) and $\mathrm{pH}$-induced unfolding stability (decreased by $\sim 0.69 \mathrm{pH}$ unit), as compared to those of WT Ngb with a single native disulfide bond of Cys46-Cys55. Moreover, the half denaturation temperature $\left(T_{m}\right)$ of $A 15 \mathrm{C}$ $\mathrm{Ngb}$ was determined to be higher than $100{ }^{\circ} \mathrm{C}$. In addition, the disulfide bond of Cys15-Cys120 has slight effects on protein function, such as an increase in the rate of $\mathrm{O}_{2}$ release by $\sim 1.4$-fold. This study not only suggests a crucial role of the artificial disulfide in protein stabilization, but also lays the groundwork for further investigation of the structure and function of $\mathrm{Ngb}$, as well as for the design of other functional heme proteins, based on the scaffold of A15C Ngb with an enhanced stability.

\section{Introduction}

Metalloproteins and metalloenzymes play crucial roles in biological systems, including electron transfer, gas transport, and catalysis. ${ }^{\mathbf{1 - 6}}$ In order to expand their functionalities, researchers have made great efforts in the design of artificial metalloproteins and metalloenzymes., ${ }^{\mathbf{1 , 7 - 1 7}}$ Since enzyme activity is affected by many factors, increasing the protein stability may ensure the artificial enzymes to be active under harsh reaction conditions, such as in presence of denaturing agents, with high temperature and in different $\mathrm{pH}$ solutions. For this purpose, various strategies have been developed in the last decade, such as rational design, ${ }^{\mathbf{1 8}}$ directed evolution, ${ }^{19}$ and computational design, ${ }^{20}$ by improving the hydrophobic and hydrogen $(\mathrm{H})$ bonding interactions within the protein scaffold. Moreover, covalent interactions such as disulfide bonds play a crucial role in protein stabilization, and design of de novo disulfide bond has shown to be useful for enhancing the protein stability. ${ }^{21-27}$

${ }^{a}$ School of Chemistry and Chemical Engineering, University of South China, Hengyang 421001, China.E-mail: linlinying@hotmail.com; ywlin@usc.edu.cn

${ }^{b}$ School of Chemistry and Chemical Engineering, Liaocheng University, Liaocheng 252059, China

${ }^{c}$ Laboratory of Protein Structure and Function, University of South China, Hengyang 421001, China

† Electronic supplementary information (ESI) available: Additional UV-Vis, CD and stopped-flow spectra. See DOI: 10.1039/c8ra10390a
Heme proteins are a major class of metalloproteins and metalloenzymes. ${ }^{4}$ To increase the protein stability, especially for the heme-binding affinity of heme proteins, a common approach is to construct a covalent heme to protein cross-link, as occurred in natural cytochrome $c$ (Cyt $c$ ) and some Cyt P450s. ${ }^{28-30}$ For example, a Cyt $c$-like covalent link (Cys-heme cross-link) has been constructed in Cyt $b_{5},{ }^{31-33}$ Cyt $b_{562},{ }^{34}$ ascorbate peroxidase, ${ }^{35}$ and myoglobin $(\mathrm{Mb}) \cdot{ }^{36}$ Moreover, other heme-protein cross-links such as Met-Heme, ${ }^{37}$ His-Heme, ${ }^{38}$ and Tyr-heme, ${ }^{39,40}$ can also be designed in artificial heme proteins. In addition to heme-protein cross-links, design of de novo disulfide bond has shown to be powerful, not only to increase the protein stability but also fine-tune the reactivity of heme proteins. ${ }^{30}$ For example, Morishima and co-workers constructed a de novo disulfide bond in $\mathrm{Mb}$ that was found to affect ligand binding dynamics. ${ }^{41}$ In recent studies, we designed a de novo disulfide bond in $\mathrm{Mb}$, which enhances both protein stability toward guanidine hydrochloride $(\mathrm{Gdn} \cdot \mathrm{HCl})$-inducing unfolding, and reactivity, such as peroxidase and nitrite reductase activities. $^{42,43}$

Neuroglobin (Ngb) was discovered in 2000 as a new member of globins, highly expressed in nerve tissues. ${ }^{44}$ In addition to the feature of a bis-His (His64/His96) heme coordination, human $\mathrm{Ngb}$ forms an intramolecular disulfide bond (Cys46-Cys55), which regulates the coordination of His64 and the binding of exogenous ligands, such as $\mathrm{O}_{2}$ and $\mathrm{CO}$, to the heme iron. ${ }^{45-48}$ 
Moreover, human Ngb has a third cysteine (Cys120), which is located near the protein surface, and is thus prone to be modified by reactive oxygen/nitrogen species (ROS/RNS) in oxidative stress conditions. ${ }^{49}$ The single free Cys120 near the protein surface may also lead to protein dimerization in purification of the recombinant Ngb protein. Therefore, Cys120 was usually replaced by a Ser to simplify protein purification and prevent protein dimerization, and functional studies were performed based on the C120S Ngb mutant. ${ }^{50-52}$ Meanwhile, Ser120 forms an H-bonding network with His23 and Glu22 that is missing in wild-type (WT) Ngb, which may affect ligand migration from the protein matrix. ${ }^{53}$ Although Cys120 has a biological role and contributes to the interface between helix $\mathrm{G}$ and the A-B loop, from a perspective of heme protein design and application, Ngb is a promising model protein. For example, H64Q Ngb can be a ligand-trap antidote for CO poisoning in practical medicine,$^{54}$ and H64A Ngb is an artificial nitrite reductase with the fastest reported activity. ${ }^{55}$

With a motivation to design Ngb mutants with advanced properties and potential applications, we anticipate that if an intramolecular disulfide bond could be constructed between Cys120 and another Cys introduced nearby, Cys120 might be protected, and the protein stability could be enhanced as well. To this end, we inspected the X-ray structure of human Ngb (PDB code $4 \mathrm{MPM}^{48}$ ), and found that Ala15 was a potential target for introducing a Cys residue, which was further supported by molecular modeling studies. As shown in this study, we found that Cys15 could indeed form an intramolecular disulfide with Cys120, as confirmed by protein mass spectrometry analysis. The additional disulfide bond (C15-C120) in A15C Ngb mutant was found to enhance both chemical and $\mathrm{pH}$ stabilities compared to those of WT Ngb with a single disulfide bond (C46C55). Moreover, the thermal stability of A15C Ngb was found to be more than $100{ }^{\circ} \mathrm{C}$, suggesting a crucial role of $\mathrm{C} 15-\mathrm{C} 120$ in protein stabilization.

\section{Results and discussion}

\section{Molecular modeling studies}

In order to construct an additional disulfide bond in human $\mathrm{Ngb}$ to protect Cys120 and stabilize the protein, we inspected the X-ray structure of human Ngb and found that Ala15 was a potential target for introducing a Cys residue. To reveal the possibility of formation of a disulfide bond between C15 and C120, we first performed a molecular modeling study for A15C $\mathrm{Ngb}$ with two intramolecular disulfide bonds. With minimization and equilibration, the simulated structure of A15C Ngb (Fig. 1A) showed that the two disulfide bonds could be well formed, with a disulfide bond distance of $2.11 \AA(\mathrm{C} 15-\mathrm{C} 120)$ and $2.05 \AA$ (C46-C55), respectively, in agreement with the X-ray structure of WT Ngb (2.02 $\AA$ for C46-C55). ${ }^{48}$ Moreover, as shown in Fig. 1B, the structure overlapped well with the X-ray structure of WT Ngb, which suggests that the formation an disulfide bond of C15-C120 causes minimal structural alterations.
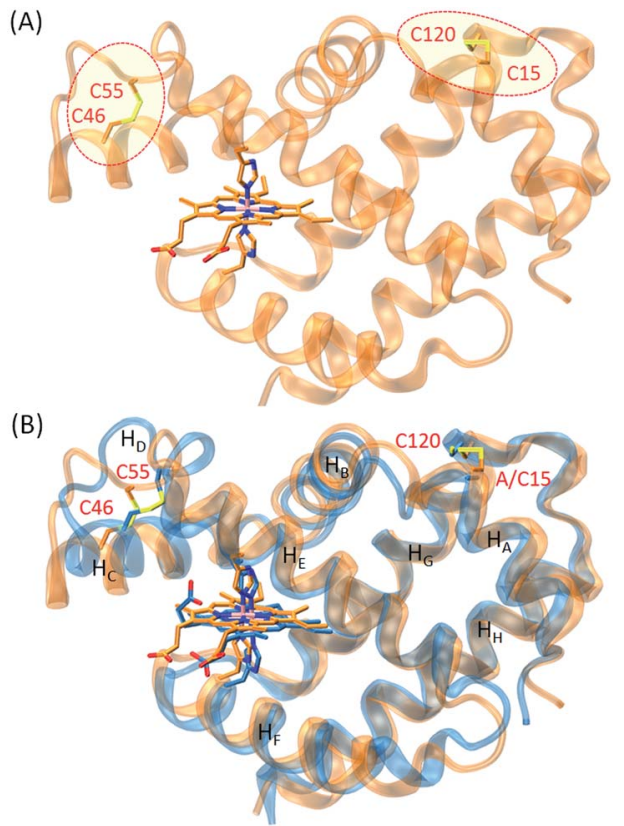

Fig. 1 (A) Modeling structure of $\mathrm{A} 15 \mathrm{C} \mathrm{Ngb}$, showing the disulfide bonds (indicated by circle lines), and (B) overlaid with the $\mathrm{X}$-ray structure of WT Ngb (blue), with the secondary structures of $\mathrm{H}_{A}-\mathrm{H}_{H}$ labeled.

\section{Spectroscopic studies}

With support by molecular modeling, we introduced an additional Cys residue at position 15 in Ngb by A15C mutation. The A15C Ngb mutant was expressed and purified using the same procedure as that for WT Ngb. UV-Vis studies showed that A15C Ngb exhibits the spectra (ferric, 413, 532 and $562 \mathrm{~nm}$; ferrous, 425, 529 and $559 \mathrm{~nm}$, Fig. 2A) with the maximum absorbance identical to those of WT Ngb in both ferric and ferrous states (Fig. S1 $\dagger$ ). ${ }^{45,56}$ Moreover, A15C Ngb was found to exhibit the CD spectrum almost identical to that of WT Ngb (Fig. 2B). These observations suggest that introduction of Cys15 does not alter the heme coordination state and the protein secondary structure.

To reveal whether Cys15 forms an intramolecular with Cys120 in A15C Ngb, we performed mass spectrometry studies using an electrospray ionization (ESI) technique, with WT Ngb as controls. As shown in Fig. 3A, the mass spectrum of WT Ngb exhibits a mass of $16931.5 \mathrm{Da}$, in agreement with previous observation for oxidized Ngb (16 $930.9 \mathrm{Da}),{ }^{46}$ which corresponds to the apo-protein of WT Ngb with an intramolecular disulfide bond (Cys46-Cys55) (calculated, 16931 Da). Note that the heme was dissociated under the detection conditions. Upon treatment by TCEP, a mass of 16 933.5 Da was observed, with an increase mass of $2 \mathrm{Da}$, which indicates the reduction of disulfide bond of Cys46-Cys55, as shown for reduced Ngb (16 932.2 Da). ${ }^{46}$ In the mass spectrum of A15C Ngb (Fig. 3B), it was interesting to observe two mass peaks (16 961.5 D and 17576.5 $\mathrm{Da})$, which correspond to the calculated apo-protein of A15C Ngb with two intramolecular disulfide bonds (16 $961 \mathrm{Da})$, and the holo-protein with heme not dissociated (17 576 Da), 
(A)

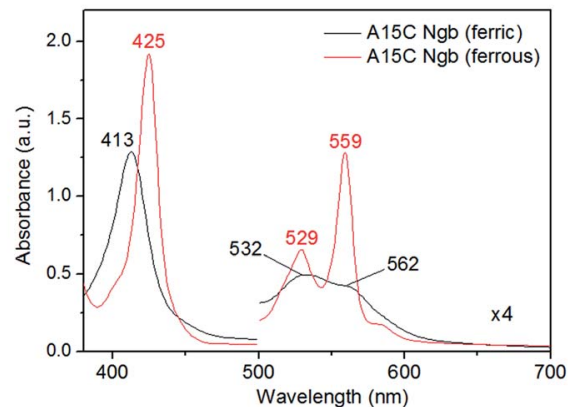

(B)

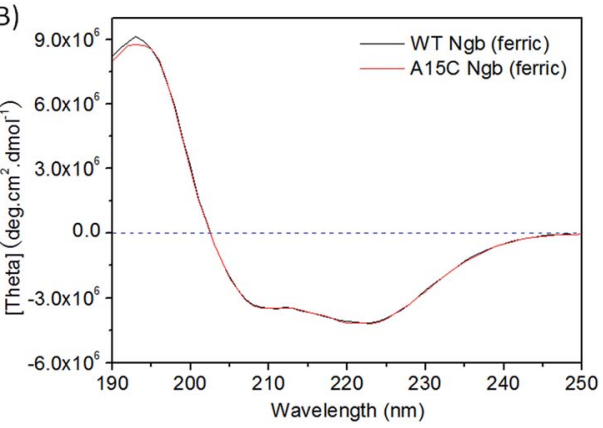

Fig. 2 Spectroscopic properties of A15C Ngb. (A) UV-Vis spectra in both oxidation states, and (B) CD spectrum in ferric state $(10 \mu \mathrm{M}$ protein in $100 \mathrm{mM}$ potassium phosphate buffer, $\mathrm{pH} 7.0,25^{\circ} \mathrm{C}$ ), with WT Ngb shown for comparison.
(A)

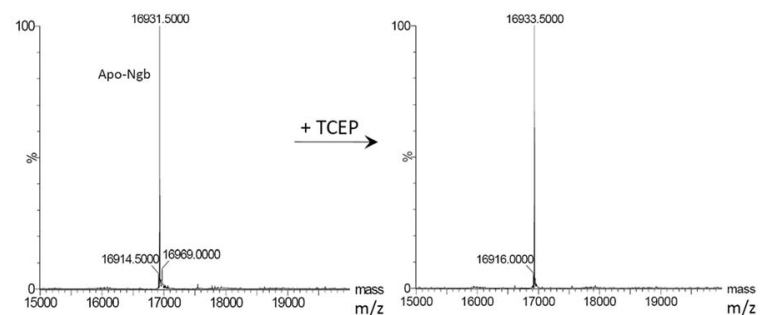

(B) 100

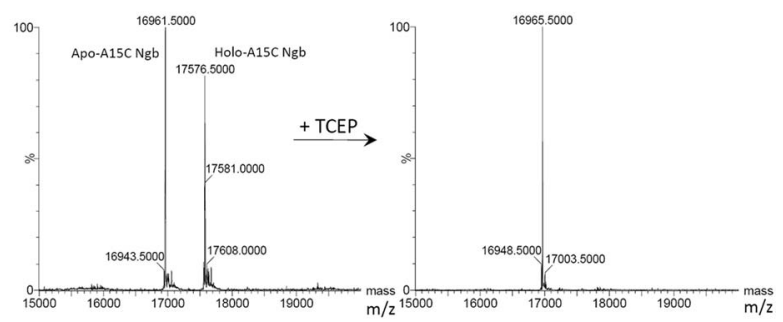

Fig. 3 ESI-MS analysis of WT Ngb (A) and A15C Ngb (B) as purified (left) and treated with reducing agent TCEP (right).

respectively. After treatment with TCEP, a single mass of 16 965.5 Da of the apo-protein was observed, with an increase mass of $4 \mathrm{Da}$, suggesting the reduction of two intramolecular disulfide bonds. The disappearance of mass peak for the holoprotein upon TCEP treatment also suggested that the heme dissociated from the protein matrix in mass determination, which, in turn, suggested that the formation of two intramolecular disulfide bonds, C46-C55 and C15-C120, may enhance the heme-binding stability of A15C Ngb under these conditions.

\section{Chemical-induced unfolding studies}

Since it is not possible to investigate A15C Ngb with one disulfide bond intact and the other cleaved, to probe the contribution of an additional disulfide bond of C15-C120 to the protein chemical stability, we first performed $\mathrm{Gdn} \cdot \mathrm{HCl}$-induced unfolding studies for both A15C Ngb and WT Ngb. As shown in Fig. $4 \mathrm{~A}$ and $\mathrm{S} 2, \uparrow$ the intensity of Soret band $(413 \mathrm{~nm})$ of both proteins decreased with increasing the concentration of $\mathrm{Gdn} \cdot \mathrm{HCl}$ to $6 \mathrm{M}$, and resulted in a shoulder peak at $\sim 370 \mathrm{~nm}$. Concurrently, the visible bands (532 $\mathrm{nm}$ and $562 \mathrm{~nm}$ ) of bis-His coordinated heme decreased with an appearance of $\sim 630 \mathrm{~nm}$. These observations suggest the release of heme from the heme pocket upon protein unfolding. Moreover, there was an isosbestic point observed in both UV-Vis spectroscopic changes, which indicates that the $\mathrm{Gdn} \cdot \mathrm{HCl}$-induced unfolding was a twostate process for both proteins.

To compare the half denaturation concentration $\left(C_{\mathrm{m}}\right)$, we plotted the spectral changes of the Soret band versus the concentration of $\mathrm{Gdn} \cdot \mathrm{HCl}$ and fitted to a normalized two-state model (Fig. 4B). The results showed that A15C Ngb exhibited a $C_{\mathrm{m}}$ value of $4.39 \pm 0.01 \mathrm{M}$, which is $\sim 0.64 \mathrm{M}$ higher than that of WT Ngb $(3.75 \pm 0.01 \mathrm{M})$. This observation suggest that the disulfide bond of C15-C120 in A15C Ngb enhances the protein chemical stability of Gdn·HCl-induced unfolding. Remarkably, the enhancement of $\sim 0.64 \mathrm{M}$ is much larger than that of a disulfide bond constructed in other heme proteins. For example, we observed an increase of $\sim 0.32 \mathrm{M}$ for $\mathrm{V} 21 \mathrm{C} / \mathrm{V} 66 \mathrm{C}$ $\mathrm{Mb}$, with a disulfide bond mimicking that in cytoglobin ( $\mathrm{Cgb}$ ), as compared to that of WT Mb upon $\mathrm{Gdn} \cdot \mathrm{HCl}$-inducing

(A)

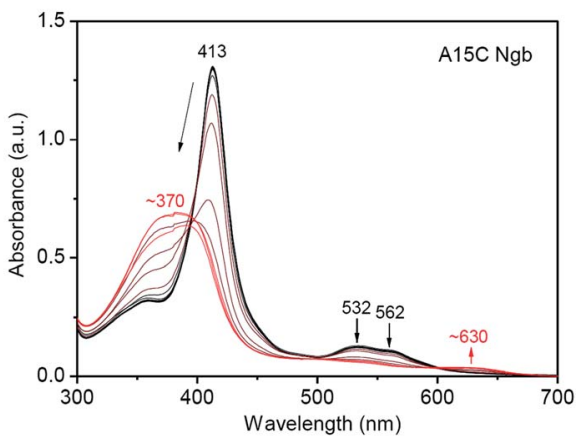

(B)

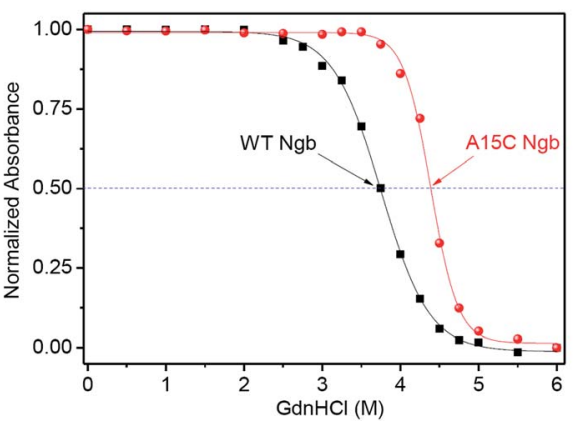

Fig. 4 UV-Vis spectra of Gdn· HCl-induced unfolding of (A) A15C Ngb (10 $\mu \mathrm{M}$ protein in $100 \mathrm{mM}$ potassium phosphate buffer, $\mathrm{pH}$ 7.0). (B) Normalized absorbance of the Soret band versus $\mathrm{Gdn} \cdot \mathrm{HCl}$ concentrations. 
unfolding. ${ }^{43}$ Fasan and co-workers showed that construction of an artificial thioether bond between a non-natural amino acid of O-2-bromoethyl Tyr and Cys in $\mathrm{Mb}$ may increase $\sim 0.24 \mathrm{M}$ for $C_{\mathrm{m}}$ upon $\mathrm{Gdn} \cdot \mathrm{HCl}$-induced unfolding. ${ }^{57}$ Moreover, Hollenberg and co-workers constructed a de novo disulfide bond close to the heme center in Cyt P450 2B1 by a double mutation of Y309C/ S360C, which reduced the protein plasticity and fine-tuned the metabolic activity. ${ }^{58}$ These observations suggest that the location for engineering a covalent bond is crucial for the enhancement of stability, as well as functional regulation.

To further evaluate the chemical stability of A15C Ngb, we performed an acid titration experiment, and compared to that of WT Ngb under the same conditions. It was shown that by titration of concentrated $\mathrm{HCl}$ into the protein solution, the Soret band decreased and shifted to $\sim 370 \mathrm{~nm}$, as well as for the visible bands (Fig. 5A and $\mathrm{S} 3 \dagger$ ). The spectral changes were similar to those occurred for $\mathrm{Gdn} \cdot \mathrm{HCl}$-induced unfolding, with appearance of an isosbestic point, which indicates that acidinduced unfolding of both proteins was also a two-state process. This was further confirmed by the well-fitting of the plots of Soret band changes versus the $\mathrm{pH}$ values (Fig. 5B). The results showed that the half denaturation $\mathrm{pH}$ value was decreased by $\sim 0.69 \mathrm{pH}$ unit for A15C Ngb (2.62 \pm 0.02$)$ compared to that of WT Ngb $(3.31 \pm 0.01)$, which indicates that the formation of an additional disulfide bond of C15-C120 increases the acid tolerance of A15C Ngb.

\section{Thermal-induced unfolding studies}

In addition to the protein chemical stability, we investigated the thermal stability of A15C Ngb, with WT Ngb as a control. We

(A)

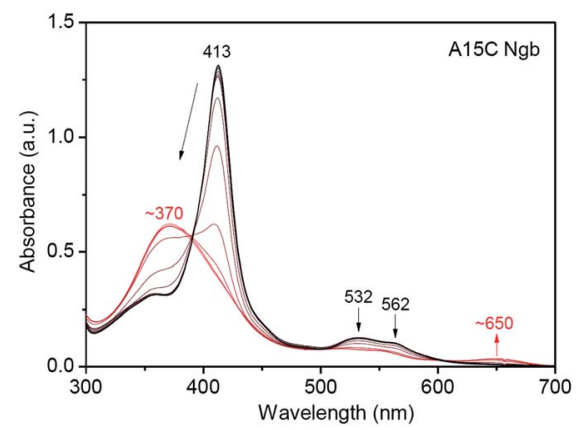

(B)

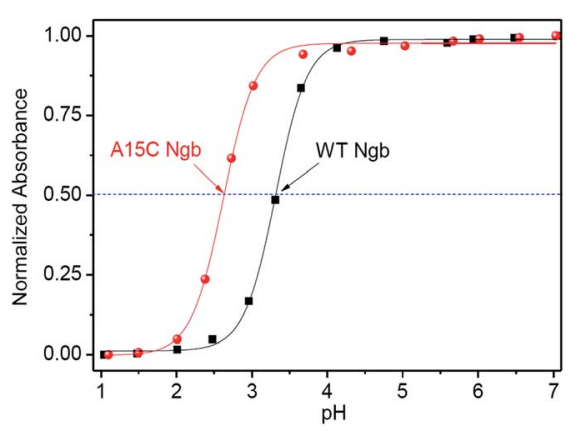

Fig. 5 UV-Vis spectra of acid-induced unfolding of (A) A15C Ngb (10 $\mu \mathrm{M})$. (B) Normalized absorbance of the Soret band versus $\mathrm{pH}$ values. first performed the far-UV CD spectroscopy studies to monitor the changes in secondary structure upon increasing temperature. As shown in Fig. $6 \mathrm{~A}$ and $\mathrm{S} 4 \dagger$ with the temperature increasing from $25{ }^{\circ} \mathrm{C}$ to $100{ }^{\circ} \mathrm{C}$, the negative Cotton effects at $208 \mathrm{~nm}$ and $222 \mathrm{~nm}$ gradually decreased, suggesting the unfolding of $\alpha$-helix structure. When the temperature reached $100{ }^{\circ} \mathrm{C}, \sim 50 \% \alpha$-helix was retained in A15C Ngb, while less than $25 \%$ was observed for WT Ngb. The plot of absorbance at $220 \mathrm{~nm}$ versus temperature showed that WT Ngb exhibits a half denaturation temperature $\left(T_{\mathrm{m}}\right)$ of $88.5{ }^{\circ} \mathrm{C}$ (Fig. 6B). Note that since A15C Ngb was only partially unfolded at $100{ }^{\circ} \mathrm{C}, T_{\mathrm{m}}$ could not be determined and was estimated to be higher than $100{ }^{\circ} \mathrm{C}$. These observations thus suggest that the second disulfide bond of C15-C120 stabilizes the secondary structure of A15C Ngb.

Moreover, we monitored the UV-Vis spectral changes upon increasing temperature (Fig. 7), which provides valuable information for the heme binding and the overall protein structure. The results showed that with the temperature increasing from $25{ }^{\circ} \mathrm{C}$ to $100{ }^{\circ} \mathrm{C}$, the Soret band of WT Ngb gradually decreased from $413 \mathrm{~nm}$ and blue shifted to $\sim 398 \mathrm{~nm}$, with disappearance of visible bands at $532 \mathrm{~nm}$ and $562 \mathrm{~nm}$ (Fig. 7A). The isosbestic point also indicated that the thermal-induced unfolding of WT Ngb was a two-state process. The spectral changes were similar to those of $\mathrm{Gdn} \cdot \mathrm{HCl}$ or acid-induced unfolding, whereas the ultimate spectrum was different, with a Soret band of $\sim 398 \mathrm{~nm}$ instead of $\sim 370 \mathrm{~nm}$ of the free heme. These observations suggest that although the heme was released from the heme pocket at high temperature, it was still associated with the protein peptide. The plot of Soret band at $413 \mathrm{~nm}$ versus temperature showed that WT Ngb exhibits a half denaturation

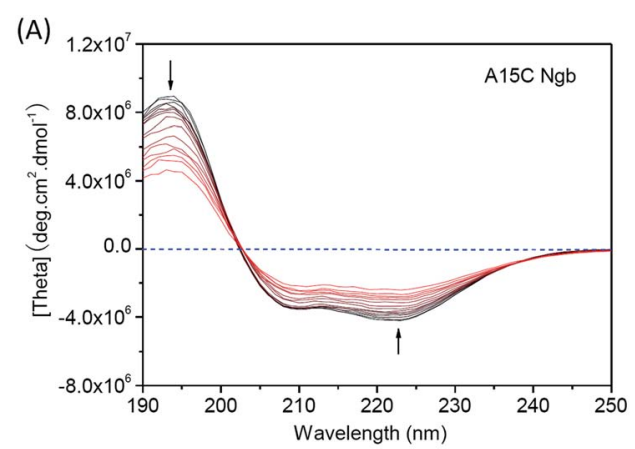

(B)

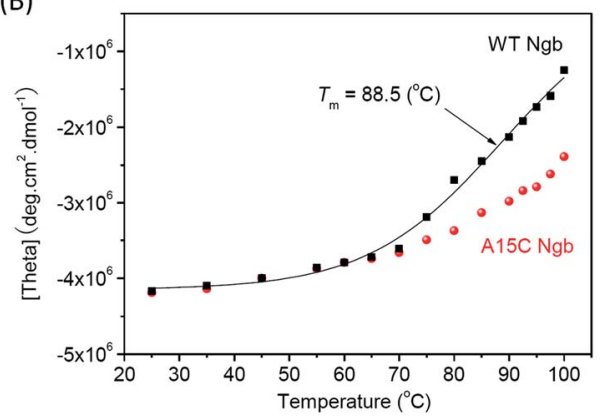

Fig. 6 CD spectra of thermal-induced unfolding of (A) A15C Ngb (10 $\mu \mathrm{M}$ protein in $100 \mathrm{mM}$ potassium phosphate buffer, $\mathrm{pH}$ 7.0). (B) Plots of absorbance at $222 \mathrm{~nm}$ versus temperature. 


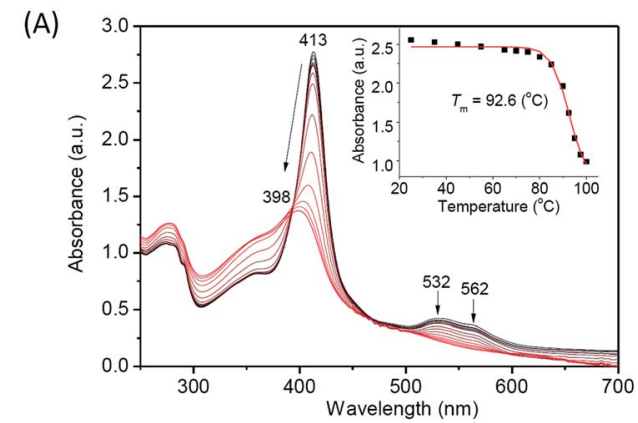

(B)

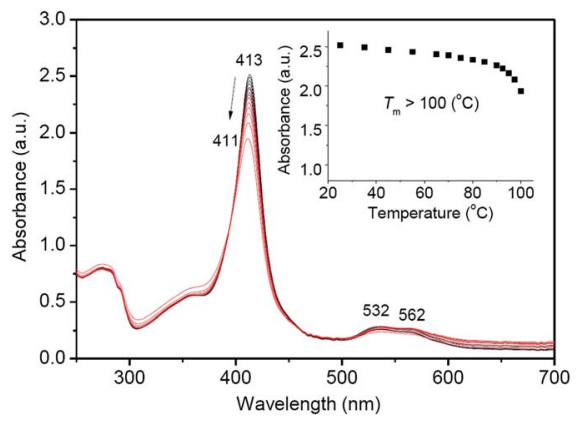

Fig. 7 UV-Vis spectra of thermal-induced unfolding of (A) WT Ngb and (B) A15C Ngb (10 $\mu \mathrm{M}$ protein in $100 \mathrm{mM}$ potassium phosphate buffer, $\mathrm{pH}$ 7.0). The plot of Soret band at $413 \mathrm{~nm}$ versus temperature was shown as an inset.

temperature $\left(T_{\mathrm{m}}\right)$ of $92.6{ }^{\circ} \mathrm{C}$ (Fig. 7A, inset). Note that this value is $\sim 4{ }^{\circ} \mathrm{C}$ higher than that determined by monitoring the changes in secondary structure, suggesting a more stability for the heme active center. In contrast to WT Ngb, A15C Ngb underwent only partial unfolding when the temperature was increased to $100{ }^{\circ} \mathrm{C}$, with slight decreases in the intensity of Soret and visible bands (Fig. 7B). Therefore, the $T_{\mathrm{m}}$ was estimated to be higher than $100{ }^{\circ} \mathrm{C}$, in agreement with the $\mathrm{CD}$ result. These results indicate that with an additional intramolecular disulfide bond of C15-C120, A15C Ngb exhibits extremely high thermal stability, and retains almost half $\alpha$-helix structure at $100{ }^{\circ} \mathrm{C}$, as well as most of the overall protein structure, where the heme was stabilized in the heme pocket.

\section{Kinetic studies}

With an enhanced protein stability of $\mathrm{A} 15 \mathrm{C} \mathrm{Ngb}$, we were further interested in testing the functional consequence of the formation of an additional disulfide bond. We first studied the autoxidation of A15C Ngb and compared to that of WT Ngb. As shown in Fig. 8A, the visible bands of the oxy-form (542 nm and $576 \mathrm{~nm}$ ) decrease in intensity over time due to the autoxidation. The plot of the absorption change at $542 \mathrm{~nm}$ versus time obeys a single-exponential decay function (Fig. 8A, inset). The rate constant of autoxidation was determined to be $5.5 \times 10^{-4} \mathrm{~s}^{-1}$ for $\mathrm{A} 15 \mathrm{C} \mathrm{Ngb}$ at $\mathrm{pH} 7.0,25{ }^{\circ} \mathrm{C}$, which is $\sim 1.38$-fold higher than that for WT Ngb under the identical conditions $\left(4.0 \times 10^{-4} \mathrm{~s}^{-1}\right)$. Note that these values $\left(\mathrm{pH} 7.0,25{ }^{\circ} \mathrm{C}\right)$ are lower than that determined for WT Ngb in previous studies at higher $\mathrm{pH}$ value $\left(2.8 \times 10^{-3} \mathrm{~s}^{-1}, \mathrm{pH} 7.5,25^{\circ} \mathrm{C}\right)^{59}$ or higher temperature $(3.8 \times$ $10^{-3} \mathrm{~s}^{-1}$, pH $\left.7.4,37^{\circ} \mathrm{C}\right) .{ }^{55}$
(A)

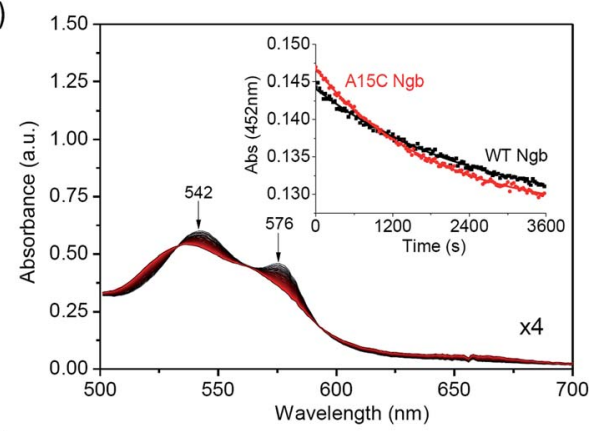

(B)

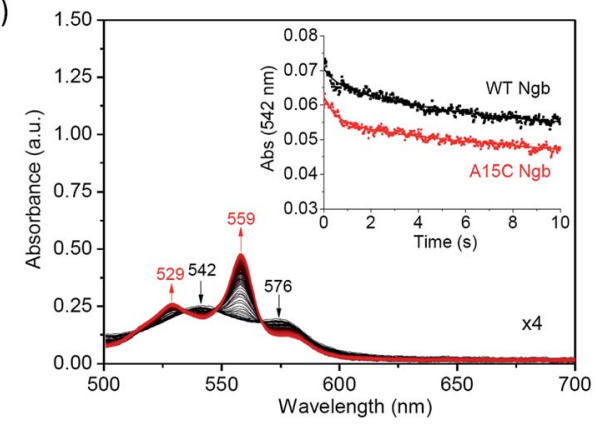

Fig. 8 (A) UV-Vis spectra of autoxidation of oxy-A15C Ngb $(10 \mu \mathrm{M}$ protein in $100 \mathrm{mM}$ potassium phosphate buffer, $\mathrm{pH}$ 7.0) for $60 \mathrm{~min}$ at $25^{\circ} \mathrm{C}$. (B) Stopped-flow spectra of oxy-A15C Ngb (5 $\mu \mathrm{M}$ protein in $100 \mathrm{mM}$ potassium phosphate buffer, $\mathrm{pH}$ 7.0), in reaction with $1 \mathrm{mM}$ dithionite in the same buffer for $10 \mathrm{~s}$ at $25^{\circ} \mathrm{C}$. The time dependent changes for the oxy-form at $542 \mathrm{~nm}$ were shown as insets, with WT $\mathrm{Ngb}$ under the same conditions shown for comparison.

Moreover, we determined the $\mathrm{O}_{2}$ release rate using stoppedflow spectroscopy upon reaction of oxy-Ngbs $(5 \mu \mathrm{M})$ with sodium dithionite $(1 \mathrm{mM})$ in $100 \mathrm{mM}$ potassium phosphate buffer (pH 7.0) at $25{ }^{\circ} \mathrm{C}$. As shown in Fig. 8B, the oxy-form (542 $\mathrm{nm}$ and $576 \mathrm{~nm}$ ) of A15C Ngb was rapidly converted to the reduced form (529 $\mathrm{nm}$ and $559 \mathrm{~nm}$ ). From the plot of the absorption change for the oxy-form at $542 \mathrm{~nm}$ versus time (Fig. 8B, inset), the rate constant of $\mathrm{O}_{2}$ release was calculated to be $0.32 \pm 0.01 \mathrm{~s}^{-1}$, which is $\sim 1.39$-fold higher than that for WT $\mathrm{Ngb}$ under the identical conditions $\left(0.23 \pm 0.01 \mathrm{~s}^{-1}\right)$. These observations suggest that the formation of a second disulfide bond of $\mathrm{C} 15-\mathrm{C} 120$ in $\mathrm{A} 15 \mathrm{C}$ Ngb slightly alters the protein function, with an increase in the rate of $\mathrm{O}_{2}$ release by $\sim 1$.4-fold.

It was interesting to observe that $\mathrm{A} 15 \mathrm{C} \mathrm{Ngb}$ with a more stable structure releases $\mathrm{O}_{2}$ easier than that of WT Ngb. The explanation for this observation may include two aspects. (1) The de novo disulfide bond of $\mathrm{C} 15-\mathrm{C} 120$ is remote from the heme center, i.e., $\sim 23 \AA$ according to the modeling structure (Fig. 1A). It may leads to long-range structural changes that impact on the heme iron coordination, as suggested by Astudillo et al. in study of C120S Ngb mutant; ${ }^{53}$ (2) the free C120 may interfere with the heme reduction process and thereby the $\mathrm{O}_{2}$ release. In a previous study, Hirota et al. introduced a cysteine to various sites on the surface of sperm whale $\mathrm{Mb}$, and showed that the heme reduction rate constant decreased in general as the heme-cysteine distance was increased. ${ }^{60}$ Therefore, the formation of C15-C120 disulfide bond in A15C Ngb may eliminate such an effect. Note that although dithionite is commonly 
used to determine $\mathrm{O}_{2}$ release of heme proteins in vitro, ${ }^{\mathbf{3 9 , 6 1}}$ for in vivo reduction of $\mathrm{Ngb}$, many biological reductants could be involved, such as GSH and redox partners Cyt $b_{5}$ and Cyt $c .^{\mathbf{6 2 , 6 3}}$

\section{Conclusions}

$\mathrm{Ngb}$ is a promising model protein for heme protein design, and in order to protect the free Cys120 in human Ngb and to enhance the protein stability, we rationally designed an additional disulfide of Cys15-Cys120 in Ngb by introduction of Cys15 in the vicinity of Cys120. As predicted by molecular modeling, Cys15 and Cys120 formed an intramolecular disulfide bond, which was confirmed experimentally by ESI-MS analysis, with WT Ngb as a control. The formation of Cys15Cys120 disulfide bond was found to have minimal structural alterations of Ngb, meanwhile, it enhanced both chemical and $\mathrm{pH}$ stabilities with respect to those of WT Ngb with a single native disulfide bond of Cys46-Cys55. Thermal-induced unfolding studies revealed that A15C Ngb retained most of the overall protein structure as high as $100{ }^{\circ} \mathrm{C}$, indicating an ultra-high thermal stability. In addition, the disulfide bond of Cys15-Cys120 remote from the heme center has only slight effects on protein function, such as an increase in the rate of $\mathrm{O}_{2}$ release by $\sim 1$.4-fold. These results suggest that an additional disulfide can be rationally designed in $\mathrm{Ngb}$, which plays a crucial role in protein stabilization. Moreover, this study lays the groundwork for further investigation of the structure and function of Ngb, as well as for the design of other functional heme proteins, based on the scaffold of A15C Ngb with an enhanced stability.

\section{Materials and methods}

\section{Protein preparation}

The pET3a plasmid DNA containing the gene of human Ngb was a gift from Prof. T. Burmester, Gutenberg University of Mainz, Germany. Ngb was expressed in E. Coli. BL21(DE3) cells and purified as previously reported. ${ }^{45}$ The A15C Ngb gene was constructed using the QuikChange Site Directed Mutagenesis Kit (Stratagene) with two primers: forward, 5'-CAG AGC TGG CGG TGT GTG AGC CGC AGC-3',

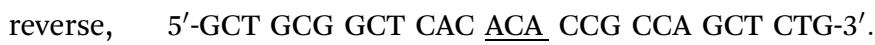
The mutation was confirmed by DNA sequencing assay, and the mutant was expressed and purified using the same procedure as that for WT Ngb. ${ }^{45}$

\section{Molecular modeling studies}

The initial structure of A15C Ngb was constructed based on the X-ray crystal structure of human Ngb (PDB code 4MPM, molecule $\mathrm{A}^{48}$ ) using program VMD 1.9. A patch of disulfide bond was applied to Cys46-Cys55 and Cys15-Cys120, respectively. The protein was solvated in a cubic box of TIP3 water, which extended $10 \AA$ away from any given protein atom. Counter ions $\left(\mathrm{Na}^{+}\right.$and $\left.\mathrm{Cl}^{-}\right)$were further added to obtain the physiological ionic strength of $0.15 \mathrm{M}$ by using the autoionize plug-in of VMD $1.9 .{ }^{64}$ The resulting system was minimized with NAMD2.9
(Nanoscale Molecular Dynamics), ${ }^{65}$ using 50000 minimization steps with conjugate gradient method at $0 \mathrm{~K}$, and equilibrated for 15000000 molecular dynamics steps (1 fs per step, 15 ns in total) at $310 \mathrm{~K}$, then further minimized for 50000 steps at $0 \mathrm{~K}$. Visualization and data analysis were done with VMD 1.9.

\section{UV-Vis and CD studies}

UV-Vis spectra of A15C Ngb and WT Ngb were collected on an Agilent 8453 spectrometer in $100 \mathrm{mM}$ potassium phosphate buffer ( $\mathrm{pH} 7.0$ ) at $25^{\circ} \mathrm{C}$. Circular dichroism (CD) spectra were collected on a Jasco 1500 spectropolarimeter equipped with a MCB-100 mini circulation bath $\left(25^{\circ} \mathrm{C}\right)$, using a cuvette with a path length of $0.1 \mathrm{~cm}$ and $1 \mathrm{~cm}$ for $190-250 \mathrm{~nm}$ and $250-$ $700 \mathrm{~nm}$, respectively. The protein concentrations of WT Ngb and $\mathrm{A} 15 \mathrm{C} \mathrm{Ngb}$ were determined with an extinction coefficient of $\varepsilon_{413 \mathrm{~nm}}=129 \mathrm{mM}^{-1} \mathrm{~cm}^{-1},^{49}$ and $\varepsilon_{413 \mathrm{~nm}}=139 \mathrm{mM}^{-1} \mathrm{~cm}^{-1}$, respectively, as calculated using the standard hemochromogen method. ${ }^{66}$

\section{Mass spectrometry}

Protein mass spectrum was measured on G2-XS QToF mass spectrometer (Waters). The desalted protein solution was mixed with $50 \%$ acetonitrile solution (acetonitrile : water, $1: 1$ ) containing $1 \%$ formic acid, and transferred into the mass spectrometer chamber for measurement by a direct injection method without performing the liquid chromatography under positive mode. The multiple $\mathrm{m} / \mathrm{z}$ peaks were transformed to the protein molecular weight by using software MaxEnt1. For reduction studies, the reducing agent tris-(2-carboxyethyl)phosphine (TCEP) was added to the protein solution at a final concentration of $10 \mathrm{mM}$, and the mixture was cultured at $37^{\circ} \mathrm{C}$ for $30 \mathrm{~min}$ before mass measurements.

\section{Gdn·HCl-induced unfolding studies}

Gdn $\cdot \mathrm{HCl}$-induced unfolding of A15C Ngb was studied by Agilent 8453 spectrometer. $10 \mu \mathrm{L}$ of $2 \mathrm{mM}$ protein sample was added into $2 \mathrm{~mL}$ of a guanidine hydrochloride $(\mathrm{Gdn} \cdot \mathrm{HCl})$ solution ( $\mathrm{pH} 7.0$ ) with various concentrations (0-6.0 M). After incubation for $30 \mathrm{~min}$, the UV-Vis spectrum was recorded. Control experiment was performed for WT Ngb under the same conditions. The unfolding transition was monitored at different $\mathrm{Gdn} \cdot \mathrm{HCl}$ concentrations through the changes of the absorbance of the Soret band. The denaturation midpoint $\left(C_{\mathrm{m}}\right)$ was calculated by fitting the absorbance of Soret band versus the concentration of $\mathrm{Gdn} \cdot \mathrm{HCl}$ to a two-state Boltzmann function (eqn (1)).

$$
A=A_{2}+\left(A_{1}-A_{2}\right) /\left(1+\mathrm{e}^{\left(C-C_{\mathrm{m}}\right) / \mathrm{d} C}\right)
$$

Here, $A$ is the absorbance of Soret band; $A_{1}$ and $A_{2}$ are the initial and final absorbance of Soret band, respectively; $C$ is the concentration of $\mathrm{Gdn} \cdot \mathrm{HCl} ; C_{\mathrm{m}}$ is the concentration of $\mathrm{Gdn} \cdot \mathrm{HCl}$ at midpoint of denaturation. 


\section{Acid-induced unfolding studies}

The acidic stability of A15C Ngb upon pH-induced unfolding was carried out on an Agilent 8453 spectrometer using a cell with a path length of $1 \mathrm{~cm}$. The temperature was controlled at $25{ }^{\circ} \mathrm{C}$ with a circulating bath. The protein sample was titrated with increasing amounts of $10 \mathrm{M} \mathrm{HCl}$ to adjust the $\mathrm{pH}$ values. After incubation at different $\mathrm{pH}$ values for $10 \mathrm{~min}$, the UV-Vis spectrum was recorded. Control experiment was performed for WT Ngb under the same conditions. The denaturation midpoint was calculated by fitting the absorbance of Soret band versus the $\mathrm{pH}$ values to a two-state Boltzmann function (eqn (2)).

$$
A=A_{2}+\left(A_{1}-A_{2}\right) /\left(1+\mathrm{e}^{\left(X-X_{0}\right) / \mathrm{d} X}\right)
$$

Here, $A$ is the absorbance of Soret band; $A_{1}$ and $A_{2}$ are the initial and final absorbance of Soret band, respectively; $X$ is the $\mathrm{pH}$ value; $X_{0}$ is the $\mathrm{pH}$ at midpoint of denaturation.

\section{Thermal-induced unfolding studies}

Thermal-induced unfolding studies of WT Ngb and A15C Ngb were performed with a Jasco 1500 spectropolarimeter equipped with a MCB-100 minicirculation bath. The protein was dissolved in potassium phosphate buffer (100 mM, pH 7.0) using a cuvette with a path length of $0.1 \mathrm{~cm}$ and $1 \mathrm{~cm}$ with their corresponding covers. The temperature was increased stepwise over the range of $25-100{ }^{\circ} \mathrm{C}$. At each temperature, the protein sample was allowed to equilibrate for $10 \mathrm{~min}$ before collecting the CD spectrum (190-250 nm) at a speed of $100 \mathrm{~nm} \min ^{-1}$ for five times, and the UV-Vis spectrum (250-700 nm) at a speed of $200 \mathrm{~nm} \min ^{-1}$ for six times. The denaturation midpoint $\left(T_{\mathrm{m}}\right)$ was calculated by fitting the ellipticity at $222 \mathrm{~nm}$ or the absorbance of Soret band versus the temperature to a two-state Boltzmann function (eqn (3)).

$$
A=A_{2}+\left(A_{1}-A_{2}\right) /\left(1+\mathrm{e}^{\left(T-T_{\mathrm{m}}\right) / \mathrm{d} T}\right)
$$

Here, $A$ is the absorbance of Soret band; $A_{1}$ and $A_{2}$ are the initial and final absorbance of Soret band, respectively; $T$ is the temperature.

\section{Kinetic studies}

The autoxidation rates of oxy-Ngb and oxy-A15C Ngb were determined using an Agilent 8453 spectrometer. The ferric protein was reduced by excess dithionite, which was removed from the solution by a PD-10 column (GE Healthcare). The reduced protein was then diluted into $\mathrm{O}_{2}$-saturated $100 \mathrm{mM}$ potassium phosphate $(\mathrm{pH} 7.0)$ to generate the oxy-form protein. The changes in intensity of the oxy-form band at $542 \mathrm{~nm}$ were monitored for $60 \mathrm{~min}$ at $25{ }^{\circ} \mathrm{C}$, and fitted to a single-exponential decay function. The $\mathrm{O}_{2}$ dissociation rates of oxy-Ngb and oxyA15C Ngb were determined using a dual mixing stopped-flow spectrophotometer (SF-61DX2 Hi-Tech KinetAsyst ${ }^{\mathrm{TM}}$ ). The prepared oxy-Ngbs $(10 \mu \mathrm{M}$ protein in $100 \mathrm{mM}$ potassium phosphate, $\mathrm{pH}$ 7.0) was mixed with an equal volume of $1 \mathrm{mM}$ sodium dithionite. The changes in intensity of the oxy-form band at $542 \mathrm{~nm}$ were monitored for $10 \mathrm{~s}$ at $25{ }^{\circ} \mathrm{C}$, and fitted to a single-exponential decay function to obtain the observed rate constant $\left(k_{\mathrm{obs}}, \mathrm{s}^{-1}\right)$.

\section{Conflicts of interest}

There are no conflicts to declare.

\section{Acknowledgements}

We gratefully thank Prof. T. Burmester of the Gutenberg University of Mainz, Germany, for graciously providing the gene of human Ngb. This work was supported by the National Natural Science Foundation of China, NSFC (31370812; 21701081) and Hunan province college students research learning and innovative experiment project (136).

\section{References}

1 Y. Lu, N. Yeung, N. Sieracki and N. M. Marshall, Nature, 2009, 460, 855-862.

2 J. Du, M. Sono and J. H. Dawson, Coord. Chem. Rev., 2011, 255, 700-716.

3 U. Liebl, J.-C. Lambry and M. H. Vos, Biochim. Biophys. Acta, 2013, 1834, 1684-1692.

4 T. L. Poulos, Chem. Rev., 2014, 114, 3919-3962.

5 J. Liu, S. Chakraborty, P. Hosseinzadeh, Y. Yu, S. Tian, I. Petrik, A. Bhagi and Y. Lu, Chem. Rev., 2014, 114, 43664469.

6 P. C. E. Moody and E. L. Raven, Acc. Chem. Res., 2018, 51, 427-435.

7 Y.-W. Lin, E. B. Sawyer and J. Wang, Chem.-Asian J., 2013, 8, 2534-2544.

8 I. D. Petrik, J. Liu and Y. Lu, Curr. Opin. Chem. Biol., 2014, 19, 67-75.

9 K. Oohora and T. Hayashi, Curr. Opin. Chem. Biol., 2014, 19, 154-161.

10 O. Shoji and Y. Watanabe, J. Biol. Inorg Chem., 2014, 19, 529539.

11 F. Nastri, M. Chino, O. Maglio, A. Bhagi-Damodaran, Y. Lu and A. Lombardi, Chem. Soc. Rev., 2016, 45, 5020-5054.

12 Y.-W. Lin, Coord. Chem. Rev., 2017, 336, 1-27.

13 S. Hirota and Y. W. Lin, J. Biol. Inorg Chem., 2018, 23, 7-25. 14 Y. Yu, C. Hu, L. Xia and J. Wang, ACS Catal., 2018, 8, 18511863.

15 F. Schwizer, Y. Okamoto, T. Heinisch, Y. Gu, M. M. Pellizzoni, V. Lebrun, R. Reuter, V. Kohler, J. C. Lewis and T. R. Ward, Chem. Rev., 2018, 118, 142-231.

16 E. N. Mirts, I. D. Petrik, P. Hosseinzadeh, M. J. Nilges and Y. Lu, Science, 2018, 361, 1098-1101.

17 L.-L. Yin, H. Yuan, C. Liu, B. He, S.-Q. Gao, G.-B. Wen, X. Tan and Y.-W. Lin, ACS Catal., 2018, 8, 9619-9624.

18 M. Lehmann and M. Wyss, Curr. Opin. Biotechnol., 2001, 12, 371-375.

19 A. Gershenson and F. H. Arnold, Genet. Eng., 2000, 22, 55-76. 20 T. J. Magliery, Curr. Opin. Struct. Biol., 2015, 33, 161-168. 21 L. J. Perry and R. Wetzel, Science, 1984, 226, 555. 
22 R. Wetzel, L. J. Perry, W. A. Baase and W. J. Becktel, Proc. Natl. Acad. Sci. U. S. A., 1988, 85, 401-405.

23 M. Matsumura, G. Signor and B. W. Matthews, Nature, 1989, 342, 291-293.

24 J. M. Chalker, G. J. Bernardes, Y. A. Lin and B. G. Davis, Chem.-Asian J., 2009, 4, 630-640.

25 J. Lee and M. Blaber, J. Mol. Biol., 2009, 393, 128-139.

26 A. A. Dombkowski, K. Z. Sultana and D. B. Craig, FEBS Lett., 2014, 588, 206-212.

27 T. Liu, Y. Wang, X. Luo, J. Li, S. A. Reed, H. Xiao, T. S. Young and P. G. Schultz, Proc. Natl. Acad. Sci. U. S. A., 2016, 113, 5910-5915.

28 C. Colas and P. R. Ortiz de Montellano, Chem. Rev., 2003, 103, 2305-2332.

29 Y.-W. Lin, Biochim. Biophys. Acta, 2015, 1854, 844-859.

30 Y.-W. Lin, Arch. Biochem. Biophys., 2018, 641, 1-30.

31 P. D. Barker, J. C. Ferrer, M. Mylrajan, T. M. Loehr, R. Feng, Y. Konishi, W. D. Funk, R. T. MacGillivray and A. G. Mauk, Proc. Natl. Acad. Sci. U. S. A., 1993, 90, 6542-6546.

32 Y.-W. Lin, W.-H. Wang, Q. Zhang, H.-J. Lu, P.-Y. Yang, Y. Xie, Z.-X. Huang and H.-M. Wu, ChemBioChem, 2005, 6, 13561359.

33 S. Hu, B. He, K.-J. Du, X.-J. Wang, S.-Q. Gao and Y.-W. Lin, ChemistryOpen, 2017, 6, 325-330.

34 P. D. Barker, E. P. Nerou, S. M. V. Freund and I. M. Fearnley, Biochemistry, 1995, 34, 15191-15203.

35 C. L. Metcalfe, O. Daltrop, S. J. Ferguson and E. L. Raven, Biochem. J., 2007, 408, 355-361.

36 H.-M. Cheng, H. Yuan, X.-J. Wang, J.-K. Xu, S.-Q. Gao, G.-B. Wen, X. Tan and Y.-W. Lin, J. Inorg. Biochem., 2018, 182, 141-149.

37 C. L. Metcalfe, M. Ott, N. Patel, K. Singh, S. C. Mistry, H. M. Goff and E. L. Raven, J. Am. Chem. Soc., 2004, 126, 16242-16248.

38 S. L. Rice, M. R. Preimesberger, E. A. Johnson and J. T. Lecomte, J. Inorg. Biochem., 2014, 141, 198-207.

39 D.-J. Yan, W. Li, Y. Xiang, G.-B. Wen, Y.-W. Lin and X. Tan, ChemBioChem, 2015, 16, 47-50.

40 D.-J. Yan, H. Yuan, W. Li, Y. Xiang, B. He, C.-M. Nie, G.-B. Wen, Y.-W. Lin and X. Tan, Dalton Trans., 2015, 44, 18815-18822.

41 T. Uchida, M. Unno, K. Ishimori and I. Morishima, Biochemistry, 1997, 36, 324-332.

42 L.-B. Wu, H. Yuan, H. Zhou, S.-Q. Gao, C.-M. Nie, X. Tan, G.-B. Wen and Y.-W. Lin, Arch. Biochem. Biophys., 2016, 600, 47-55.

43 L.-L. Yin, H. Yuan, K.-J. Du, B. He, S.-Q. Gao, G.-B. Wen, X. Tan and Y.-W. Lin, Chem. Commun., 2018, 54, 4356-4359.

44 T. Burmester, B. Weich, S. Reinhardt and T. Hankeln, Nature, 2000, 407, 520-523.

45 S. Dewilde, L. Kiger, T. Burmester, T. Hankeln, V. BaudinCreuza, T. Aerts, M. C. Marden, R. Caubergs and L. Moens, J. Biol. Chem., 2001, 276, 38949-38955.
46 D. Hamdane, L. Kiger, S. Dewilde, B. N. Green, A. Pesce, J. Uzan, T. Burmester, T. Hankeln, M. Bolognesi, L. Moens and M. C. Marden, J. Biol. Chem., 2003, 278, 51713-51721.

47 L. Astudillo, S. Bernad, V. Derrien, P. Sebban and J. Miksovska, Biophys. J., 2010, 99, L16-L18.

48 B. G. Guimaraes, D. Hamdane, C. Lechauve, M. C. Marden and B. Golinelli-Pimpaneau, Acta Crystallogr., Sect. D: Biol. Crystallogr., 2014, 70, 1005-1014.

49 S. Nicolis, E. Monzani, C. Ciaccio, P. Ascenzi, L. Moens and L. Casella, Biochem. J., 2007, 407, 89-99.

50 M. Tiso, J. Tejero, S. Basu, I. Azarov, X. Wang, V. Simplaceanu, S. Frizzell, T. Jayaraman, L. Geary, C. Shapiro, C. Ho, S. Shiva, D. B. Kim-Shapiro and M. T. Gladwin, J. Biol. Chem., 2011, 286, 18277-18289.

51 A. Bocahut, V. Derrien, S. Bernad, P. Sebban, S. SacquinMora, E. Guittet and E. Lescop, J. Biol. Inorg Chem., 2013, 18, 111-122.

52 S. Trashin, M. de Jong, E. Luyckx, S. Dewilde and K. De Wael, J. Biol. Chem., 2016, 291, 18959-18966.

53 L. Astudillo, S. Bernad, V. Derrien, P. Sebban and J. Miksovska, Biochemistry, 2012, 51, 9984-9994.

54 I. Azarov, L. Wang, J. J. Rose, Q. Xu, X. N. Huang, A. Belanger, Y. Wang, L. Guo, C. Liu, K. B. Ucer, C. F. McTiernan, C. P. O'Donnell, S. Shiva, J. Tejero, D. B. Kim-Shapiro and M. T. Gladwin, Sci. Transl. Med., 2016, 8, 368ra173.

55 J. Tejero, C. E. Sparacino-Watkins, V. Ragireddy, S. Frizzell and M. T. Gladwin, Biochemistry, 2015, 54, 722-733.

56 H.-X. Liu, L. Li, B. He, S.-Q. Gao, G.-B. Wen and Y.-W. Lin, Dalton Trans., 2018, 47, 10847-10852.

57 E. J. Moore, D. Zorine, W. A. Hansen, S. D. Khare and R. Fasan, Proc. Natl. Acad. Sci. U. S. A., 2017, 114, 1247212477.

58 H. Zhang, C. Kenaan, D. Hamdane, G. H. Hoa and P. F. Hollenberg, J. Biol. Chem., 2009, 284, 25678-25686.

59 A. Fago, C. Hundahl, S. Dewilde, K. Gilany, L. Moens and R. E. Weber, J. Biol. Chem., 2004, 279, 44417-44426.

60 S. Hirota, K. Azuma, M. Fukuba, S. Kuroiwa and N. Funasaki, Biochemistry, 2005, 44, 10322-10327.

61 S. Nagao, H. Osuka, T. Yamada, T. Uni, Y. Shomura, K. Imai, Y. Higuchi and S. Hirota, Dalton Trans., 2012, 41, 1137811385.

62 P. Ascenzi, A. di Masi, L. Leboffe, M. Fiocchetti, M. T. Nuzzo, M. Brunori and M. Marino, Mol. Aspects Med., 2016, 52, 1-48. 63 M. Fiocchetti, M. Cipolletti, V. Brandi, F. Polticelli and P. Ascenzi, J. Mol. Recognit., 2017, e2654.

64 W. Humphrey, A. Dalke and K. Schulten, J. Mol. Graphics, 1996, 14(33-38), 27-38.

65 L. Kalé, R. Skeel, M. Bhandarkar, R. Brunner, A. Gursoy, N. Krawetz, J. Phillips, A. Shinozaki, K. Varadarajan and K. Schulten, J. Comput. Phys., 1999, 151, 283-312.

66 M. Morrison and S. Horie, Anal. Biochem., 1965, 12, 77-82. 